\title{
Inhibitors of Protein Kinase C Prevent Enhancement of Calcium Current and Action Potentials in Peptidergic Neurons of Aplysia
}

\author{
P. Jeffrey Conn, ${ }^{1, a}$ Judith A. Strong, ${ }^{2, b}$ and Leonard K. Kaczmarek ${ }^{1,2}$ \\ Departments of ${ }^{1}$ Pharmacology and ${ }^{2}$ Physiology, Yale University School of Medicine, New Haven, Connecticut 06510
}

Following brief stimulation of an afferent pathway, the bag cell neurons of Aplysia undergo a dramatic change in excitability, resulting in a prolonged discharge of spontaneous action potentials. During the discharge, the action potentials of the bag cell neurons become enhanced in height and width. The afterdischarge triggers release of neuroactive peptides that initiate egg-laying behavior in this animal. Evidence suggests that changes in excitability of the bag cell neurons may be mediated by activation of protein kinase $C$ (PKC) and CAMP-dependent protein kinase (CAMP-PK). PKC activators, such as the phorbol ester TPA (12-O-tetradecanoyl-13-phorbol acetate), enhance the amplitude of action potentials in isolated bag cell neurons in cell culture. These agents act by unmasking a previously covert species of voltage-dependent calcium channel resulting in an increase in calcium current. In the accompanying paper (Conn et al., 1989), we showed that $\mathrm{H}-7$, a protein kinase inhibitor, inhibits the effect of TPA, and is a selective inhibitor of PKC relative to CAMP-PK in these cells. We now report that another PKC inhibitor, sphinganine, also inhibits the effect of TPA on action potential height and calcium current in cultured bag cell neurons, and that $\mathrm{N}$-acetylsphinganine, an inactive sphinganine analog, fails to inhibit the effects of PKC activators. Although both $\mathrm{H}-7$ and sphinganine prevent the effects of TPA when added prior to TPA addition, neither compound reverses the effects of TPA when added after the action potentials have already become enhanced by TPA. This suggests that a transient activation of PKC may result in a longlasting change in excitability of these neurons that persists in the absence of PKC activity. We then used the PKC inhibitors to evaluate the contribution of PKC to the afterdischarge that occurs in bag cell neurons in the intact abdominal ganglion. Extracellular recordings revealed that neither $\mathrm{H}-7$ nor sphinganine prevented the initiation of an afterdischarge in bag cell clusters. However, intracellular recordings of bag cell neurons within clusters revealed that both $\mathrm{H}-7$ and sphinganine inhibited the heightening and broadening of action potentials that normally occurs within the first 2 min of an

\footnotetext{
Received Nov. 27. 1987; revised June 24, 1988; accepted June 27, 1988.

This work was supported by grants NS-18492 to L.K.K. and PHS Fellowships NS-07136-08 and NF-08228-01 to P.J.C.

Correspondence should be addressed to Dr. Leonard K. Kaczmarek, Department of Pharmacology, Yale University School of Medicine, 333 Cedar Street, New Haven, CT 06510.

a Present address: Department of Pharmacology, Emory University School of Medicine, Atlanta, GA 30322

b Present address: Department of Biological Sciences, Purdue University, West Lafayette, IN 47907.

Copyright (C) 1989 Society for Neuroscience $0270-6474 / 89 / 020480-08 \$ 02.00 / 0$
}

afterdischarge and persists for the duration of the discharge. These data suggest that the PKC-induced unmasking of the covert calcium channel contributes to the enhancement of action potentials during the afterdischarge.

Interaction of a neurotransmitter with its postsynaptic receptor often induces a transient change in excitability of the effector neuron that lasts milliseconds to seconds. However, it has become increasingly clear that brief activation of neurotransmitter receptors (and the protein kinases that are subsequently activated) may also induce more prolonged changes in the excitability of effector neurons that last minutes, hours, or even days or months. A number of neurotransmitters alter excitability of postsynaptic cells by activating protein kinase $\mathrm{C}$ (PKC), a calcium/diacylglycerol/phospholipid-dependent protein kinase. Activation of PKC may influence the properties of neurons in a variety of distinct ways (Miller, 1986; Kaczmarek, 1987, for reviews). For example, evidence has accumulated for PKC-induced changes in conductances of ion channels (DeReimer et al., 1985; Alkon et al., 1986; Farley and Auerbach, 1986; Madison et al., 1986; Malenka et al., 1986) changes in rate of neurotransmitter synthesis (Berry, 1986; Wang et al., 1986) or release (Publicover, 1985; Zurgil and Zisapel, 1985; Nichols et al., 1987; Shapira et al., 1987), changes in the cytoskeletal function (Werth et al., 1983; Litchfield and Bell, 1986), generation of eicosanoids (Ho and Klcin, 1987), or regulation of the sensitivity of neurotransmitter receptors (Kelleher et al., 1984; Sibley et al., 1984; Vicentini et al., 1985).

The bag cell neurons of Aplysia are an excellent model system for studying protein kinase-mediated changes in electrical excitability (Kaczmarek et al., 1986; Strong and Kaczmarek, 1987). In the resting state, the bag cell neurons have a relatively high resting potential and are electrically silent. However, brief (5$10 \mathrm{sec}$ ) activation of the afferent input to these cells causes the cells to depolarize and undergo a prolonged (20-40 min) afterdischarge of calcium-dependent action potentials. This increased excitability is followed by a refractory period, lasting about $20 \mathrm{hr}$, during which no further discharge can be initiated (Kupfermann and Kandel, 1970; Kaczmarek and Kauer, 1983).

Several lines of evidence suggest that PKC activation contributes to the transition of bag cell neurons from an inexcitable state to a state of repetitive firing. The afterdischarge is accompanied by an increase in phosphoinositide hydrolysis (Fink et al., 1988) and, by inference, an activation of PKC. Furthermore, PKC activators, such as TPA (12-O-tetradecanoyl-13-phorbol acetate) enhance action potentials in bag cell neurons grown in primary culture by enhancing the calcium current in these cells (DeReimer et al., 1985; Strong et al., 1987). Evidence strongly 
suggests that the effect of TPA on bag cell excitability is mediated by activation of PKC since it is mimicked by other PKC-activating phorbol esters, diacylglycerols, or by direct microinjection of the purified enzyme, but not by the addition of phorbol esters that do not activate PKC (DeReimer et al., 1985). An intriguing aspect of the TPA-induced increase in calcium current in bag cell neurons is that it is brought about by expression of a novel species of calcium channel, a covert channel that is not present in untreated cells (Strong et al., 1987). In control cells, only one species of calcium channel is observed. This channel has a unitary conductance of about $12 \mathrm{pS}$. After treatment with PKC activators, a second species of calcium channel appears, which has a unitary conductance of about $24 \mathrm{pS}$.

Pharmacological inhibitors of PKC act at 1 of 2 sites. Agents such as H-7 (1-[5-isoquinolinesulfonyl]-2-methyl piperazine) appear to act at the catalytic site of the enzyme (Hidaka et al., 1984). In the accompanying paper (Conn et al., 1989), we showed that the effect of TPA is inhibited by incubation of bag cell neurons with $\mathrm{H}-7$ and that $\mathrm{H}-7$ is a selective inhibitor of $\mathrm{PKC}$ relative to cAMP-dependent protein kinase (cAMP-PK) in intact bag cell neurons. Another structurally distinct class of agents, exemplified by the lipid sphinganine (erythro-dihydrosphingosine), compete with diacylglycerol at the regulatory site of the enzyme (Hannun et al., 1986; Merrill et al., 1986; Wilson et al., 1986). In the present studies, we show that sphinganine also inhibits the TPA-induced increase in calcium current, which is caused by the unmasking of the covert $24 \mathrm{pS}$ species of calcium channel. In addition we have found that sphinganine and $\mathrm{H}-7$ prevent the enhancement of action potentials that normally occurs during an afterdischarge, suggesting that the unmasking of the covert calcium channel by PKC contributes to such enhancement. Finally, we report that, although pretreatment with PKC inhibitors prevents the effect of TPA on action potentials, these inhibitors have no effect when added after action potentials have been enhanced. We suggest that transient activation of PKC is sufficient to induce a long-lasting enhancement of calcium current. This is accomplished by unmasking a covert species of calcium channel that remains active after PKC is inhibited. Some of the data reported here have been reported previously in abstract form (Conn et al., 1987, 1988).

\section{Materials and Methods}

Drugs. Collagenase (Boehringer Mannheim) and elastase (Type 1, Sigma) were prepared fresh daily in artificial seawater (ASW). Sphinganine (Sigma) and $N$-acetylsphinganine were kept under nitrogen at $-20^{\circ} \mathrm{C}$ as a $10 \mathrm{~mm}$ stock solution in absolute ethanol. $N$-Acetylsphinganine was a generous gift of Dr. Robert M. Bell (Duke University). Sources and handling of TPA and H-7 are discussed in the accompanying paper (Conn et al., 1989).

Animals and cell culture. Aplysia californica (150-400 gm) were obtained from Alacrity Marine Services (Redondo Beach, CA) and kept at $14^{\circ} \mathrm{C}$. Cells were cultured in ASW with modified Eagle's medium (ASW-MEM) as described in the accompanying paper (Conn et al., 1989).

Measurement of action potentials in cultured bag cell neurons. Methods for intracellular recording and current injection were as described in the accompanying paper (Conn et al., 1989). In cases in which the effect of TPA upon action potential shape was measured, TPA was added after stable action potentials were obtaincd. Action potential height was measured from the point of upward deflection to the peak.

Whole-cell voltage-clamp in cultured bag cell neurons. Cultured bag cell neurons were dialyzed and voltage-clamped as in the accompanying paper (Conn et al., 1989). In cases in which the effect of sphinganine or $\mathrm{N}$-acetylsphinganine was measured, these compounds were added at least $15 \mathrm{~min}$ prior to voltage-clamp recordings.

Measurement of activity of single calcium channels in cultured bag cell neurons. Bag cell neurons were grown in MEM-ASW in which magnesium sulfate was replaced with magnesium chloride. Single-channel recordings were made with Sylgard-coated cell-attached pipettes as described previously (Strong et al., 1987). The patch pipettes contained (in $\mathrm{mM}$ ) $\mathrm{BaCl}_{2}, 185 ;$ TEA-Cl, 260; $\mathrm{CsCl}, 10 ; 4$-aminopyridine, 20 ; and HEPES-TEA-OH, 15 (pH 7.8). When the effect of TPA was determined, TPA was added at least 15 min prior to recording. When sphinganine was used, it was added at least $15 \mathrm{~min}$ prior to addition of TPA.

Extracellular recordings from bag cell neurons. The abdominal ganglion was dissected and placed in ASW in a recording chamber at $14^{\circ} \mathrm{C}$. A recording suction electrode was placed on the rostral end of one of the bag cell clusters. This allows the recording of large compound action potentials representing synchronous firing of all of the bag cell neurons within a cluster. A stimulating suction electrode was placed on the ipsilateral pleuroabdominal connective approximately $1-2 \mathrm{~cm}$ distal to the bag cell cluster, and afterdischarges were elicited by $15 \mathrm{sec}$ stimulus trains $(8-20 \mathrm{~V}, 6 \mathrm{~Hz}, 2.5 \mathrm{msec}$ pulse width) applied to the connective nerve. Afterdischarge recordings were observed on a Nicolet 3091 oscilloscope and stored using a Grass chart recorder.

Intracellular recordings from bag cell neurons in the intact abdominal ganglion. Abdominal ganglia were removed and incubated for $2-3 \mathrm{hr}$ at room temperature in ASW containing $1-2 \mathrm{mg} / \mathrm{ml}$ collagenase and $0.5 \mathrm{mg} / \mathrm{ml}$ elastase to soften the overlying connective tissue and allow microelectrode penetration into bag cell neurons. Ganglia treated in this manner were pinned to the base of a recording chamber containing ASW. Glass microelectrodes were filled with $3 \mathrm{M} \mathrm{KCl}$ and had resistances of 20-60 M . Recordings were made through a WPI S7071A electrometer, and electrical activity was recorded on a Nicolet 3091 oscilloscpe and a Grass chart recorder. An extracellular recording electrode was placed on a bag cell cluster and an extracellular stimulating electrode was placed on the pleuroabdominal connective nerve as described above. $\Lambda \mathrm{fter}$ penetration of single bag cell neurons within the clusters, the cells were monitored for several minutes until a stable resting potential was obtained. Afterdischarges were then elicited from bag cell clusters by stimulation of the pleuroabdominal connective as described above. Action potential height was measured from the base of the action potential at the point of inflection to the peak of the action potential. Action potential width was measured at half-maximal amplitude.

\section{Results}

Sphinganine prevents TPA-induced enhancement of action potentials

Incubation of cultured bag cell neurons with the PKC-activating phorbol ester TPA results in enhancement of the height of evoked action potentials (DeReimer et al., 1985). In the present study we found that incubation of bag cell neurons with the PKC inhibitor sphinganine $(10 \mu \mathrm{M})$ for at least $15 \mathrm{~min}$ before addition of TPA completely blocked the effect of TPA on action potentials (Fig. 1). The effect of TPA was not inhibited by incubation in $10 \mu \mathrm{M} N$-acetylsphinganine (Fig. 1), an analog of sphinganine that does not inhibit PKC (Wilson et al., 1986).

\section{Sphinganine prevents TPA-induced increases in calcium current}

Consistent with previous results (DeReimer et al., 1985), the amplitude of voltage-dependent calcium current in internally dialyzed, voltage-clamped bag cell neurons that had been exposed to $20 \mathrm{nM}$ TPA before and during dialysis was found to be approximately twice that of control neurons isolated from the same cluster. This doubling of calcium current was observed at all membrane potentials (Fig. $2 A$ ). This effect of TPA on calcium current was completely inhibited by incubation of bag cell neurons with $10 \mu \mathrm{M}$ sphinganine for $15 \mathrm{~min}$ prior to addition of TPA. The mean $( \pm \mathrm{SEM})$ peak calcium current density at 10 $\mathrm{mV}$ was $6.6 \pm 1.0 \mathrm{nA} / \mathrm{nF}$ in control cells, $15.4 \pm 1.5 \mathrm{nA} / \mathrm{nF}$ in TPA-treated cells, and $6.1 \pm 0.9 \mathrm{nA} / \mathrm{nF}$ in TPA-treated cells that had been treated with $10 \mu \mathrm{M}$ sphinganine prior to addition of TPA ( $n=4$ each group). As we have reported for the protein 
Figure 1. Sphinganine prevents TPAinduced enhancement of action potentials in cultured bag cell neurons. The action potentials shown were evoked by injection of $0.1 \mathrm{nA}$ of depolarizing current in to bag cell neurons before addition of TPA and $30 \mathrm{~min}$ after addition of $20 \mathrm{nM}$ TPA. Cells were treated with either $10 \mu \mathrm{M} N$-acetylsphinganine $(A)$ or $10 \mu \mathrm{M}$ sphinganine $(B)$ at least 15 min before TPA addition. These data are representative of $3 \mathrm{~N}$-acetylsphinganine-treated cells and 3 sphinganinetreated cells taken from 3 different animals.

\section{A. N-Acetylsphinganine}
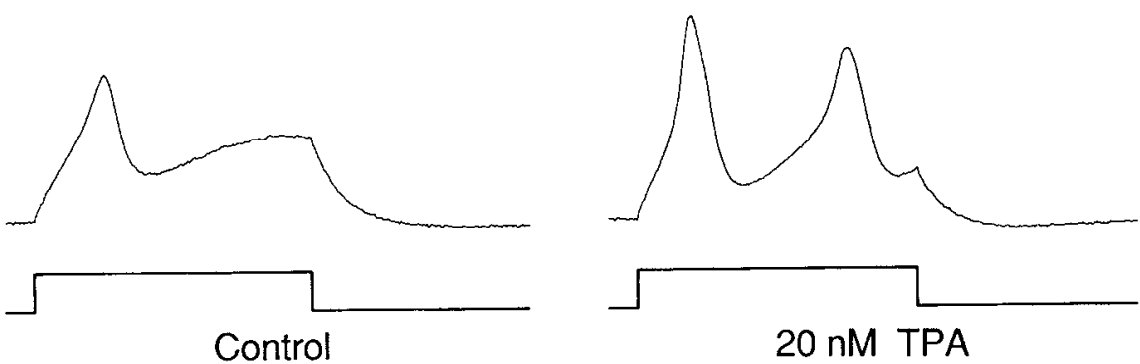

B. Sphinganine
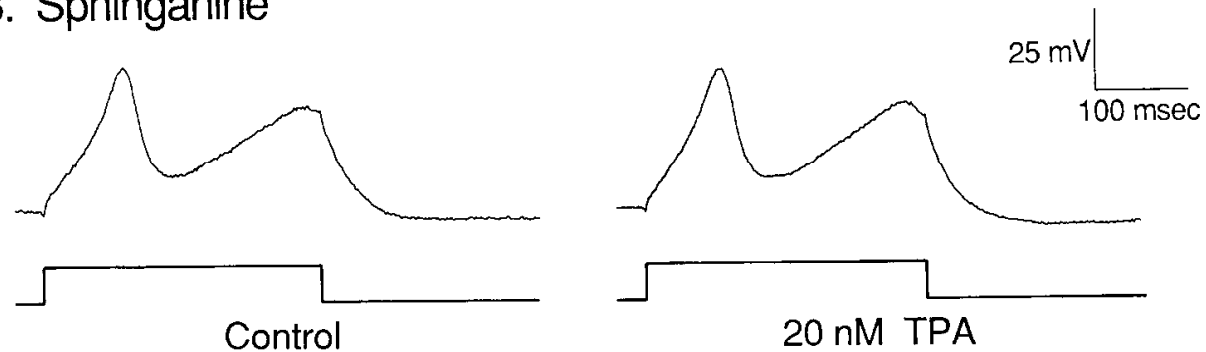

kinase inhibitor H-7 (Conn et al., 1989), $10 \mu$ M sphinganine had no effect on control calcium current in cells that had not been treated with TPA ( $\Gamma i g .2 B$ ). Furthermore, the TPA-induced increase in calcium current was not inhibited by preincubation of bag cell neurons in $10 \mu \mathrm{M} \mathrm{N}$-acetylsphinganine (Fig. 2C). This is consistent with the observation that $N$-acetylsphinganine does not inhibit TPA-induced enhancement of action potentials and suggests that the effect of sphinganine is not mediated by a nonspecific membrane-perturbing effect of the drug.
Single-channel data suggest that the inhibitory effect of sphinganine on TPA-induced increases in calcium current is mediated by inhibition of TPA-induced expression of the covert, largeconductance calcium channel. As described previously (Strong et al., 1987), the large conductance ( 24 pS) channel can usually be detected in approximately one-third of patches on TPAtreated cells. However, no large-conductance channels were detected in patches on cells that had been treated with sphinganine at least $15 \mathrm{~min}$ prior to addition of TPA (Fig. 3).
Figure 2. Sphinganine prevents TPAinduced enhancement of calcium current in cultured bag cell neurons. $A$, Current traces elicited by depolarizing voltage-clamp steps to the indicated potentials. Traces shown are representative of 4 control cells, 4 cells that were treated with $20 \mathrm{~nm}$ TPA at least $15 \mathrm{~min}$ prior to voltage clamping and 4 TPAtreated cells that were incubated with $10 \mu \mathrm{M}$ sphinganine $15 \mathrm{~min}$ prior to addition of $20 \mathrm{nM}$ TPA (all cells from a single animal). $B$, Mean ( \pm SEM) $I-V$ (current-voltage) curves are shown from a set of control cells $(n=3)$ and cells treated with $10 \mu \mathrm{M}$ sphinganine in the absence of TPA $(n=5)$. All cells were from the same animal. In cells from another animal peak currents were measured at $20 \mathrm{mV}$ only, yielding data in agreement with those shown in $B$ (control $=5.81 \pm 0.66 \mathrm{nA} / \mathrm{nF}, n=6$; sphinganine $=5.67 \pm 1.47 \mathrm{nA} / \mathrm{nF} ; n=$ 6). $C$, Mean ( \pm SEM) $I-V$ curves from a set of control cells $(n=4$ cells from 1 animal) and a set of cells treated with 20 nM TPA ( $n=5$ cells from 1 animal) $15 \mathrm{~min}$ after addition of $10 \mu \mathrm{M} \mathrm{N}$-acetylsphinganine. For the $I-V$ curves, peak inward currents were normalized by cell capacitance (estimated by integrating the unfiltered current transient seen during a brief hyperpolarizing pulse).
A.

Control
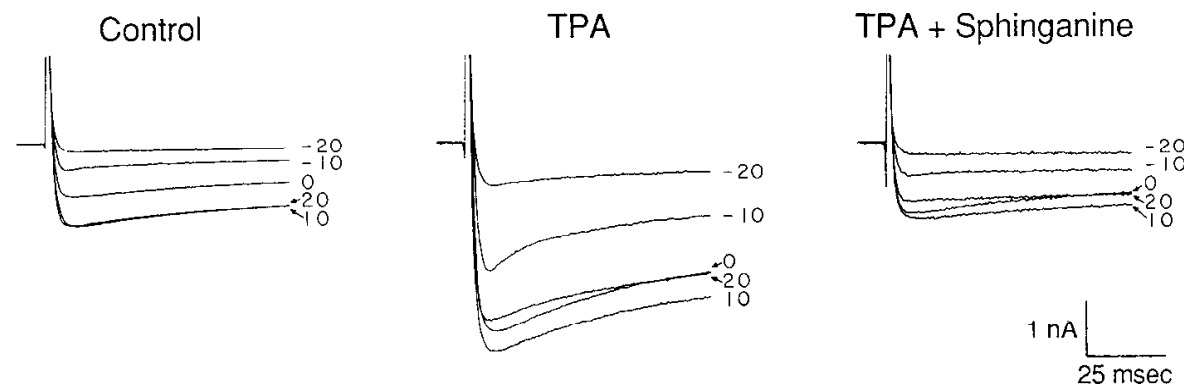

B.

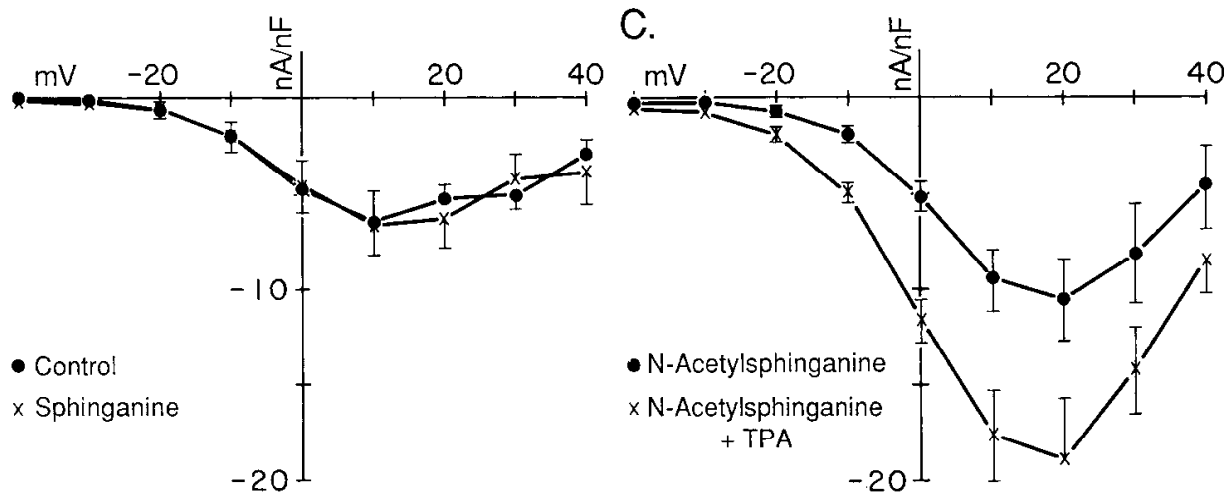


Effect of sphinganine and $\mathrm{H}-7$ on the afterdischarge of bag cell neurons in the intact abdominal ganglion

Although it has been shown that the afterdischarge in bag ccll neurons is accompanied by increases in phosphoinositide hy= drolysis (Fink et al., 1988) and that activation of PKC induccs expression of a covert calcium channel in cultured bag cell neurons (Strong et al., 1987), the role of PKC and the covert calcium channel in transition of the bag cell neurons from an inexcitable to a repetitively firing state in the intact abdominal ganglion has not been investigated. Having established that sphinganine and $\mathrm{H}-7$ prevent $\mathrm{PKC}$-induced expression of the large-conductance calcium channel, we used these compounds to determine the effect of inhibition of PKC (and expression of the covert calcium channel) on initiation and maintenance of the afterdischargc.

We found that incubation of abdominal ganglia in H-7 (100 $\mu \mathrm{M})$ or sphinganine $(25 \mu \mathrm{M})$ for at least 15 min prior to stimulation of the pleuroabdominal connective nerve had no effect on the initiation of discharges as assessed by extracellular recordings (Fig. 4). In all abdominal ganglia tested, the basic characteristics of the afterdischarge appeared normal, with an initial phase of rapid firing of action potentials $(4-6 \mathrm{~Hz}$ ) followed by a prolonged phase in which action potentials fire at a slower rate (Kaczmarek et al., 1982). We did note, however, that afterdischarges tended to be of longer duration in abdominal ganglia that had been treated with the PKC inhibitors. The duration of afterdischarges in $\mathrm{H}$-7-treated ganglia (mean \pm SEM duration $=87 \pm 16 \mathrm{~min}, n=4$ ) was statistically different from that in control ganglia ( $30 \pm 5 \mathrm{~min}, n=7 ; p<0.01$ ). Although sphinganine also frequently prolonged discharges (up to $120 \mathrm{~min}$ ), its cffect was morc variable than that of $\mathrm{H}-7$ and was not statistically significant ( $48 \pm 15 \mathrm{~min}, n=7 ; p=0.255$ ). At the end of discharges in $\mathrm{H}-7$ or sphinganine, the bag cell neurons entered the normal prolonged inhibited period during which further stimulation of the pleuroabdominal connective nerves failed to trigger further long-lasting discharges.

Although the inhibitors of PKC did not prevent the onset of the discharge, we found that they had a very marked effect on the change in action potential shape during the discharge. At the onset of afterdischarges in untreated ganglia, there is a significant increase in the calcium component of bag cell action potentials. This is observed as an increase in action potential height and width within 2-3 min of initiation of afterdischarges in normal, calcium-containing medium (Kaczmarek et al., 1982; see also Fig. 5). In the present studies we found that inhibition of PKC with $\mathrm{H}-7$ or sphinganine prevented the modulation of action potential shape that occurs during an afterdischarge (Fig. 5). There was no enhancement of action potential height during the afterdischarge in the presence of either sphinganine or $\mathrm{H}-7$, nor was there an enhancement of action potential width in the presence of sphinganine. The data for the mean spike width during discharges initiated in the presence of $\mathrm{H}-7$ indicated that some spike broadening did occur but that spike broadening was diminished relative to control. However, the increascd variability and increased spike width in $\mathrm{H}$-7-treated ganglia is due to a substantial increase in spike width in 1 out of 4 ganglia. There was no spike broadening in the remaining 3 ganglia. This may be due to the fact that H-7 does not completely inhibit the effect of TPA on calcium current at the concentration used (Conn et al., 1989). We did not increase H-7 concentrations above $100 \mu \mathrm{M}$ because of the possibility of inhibiting calcium/ calmodulin-dependent protein kinase at higher concentrations
A.

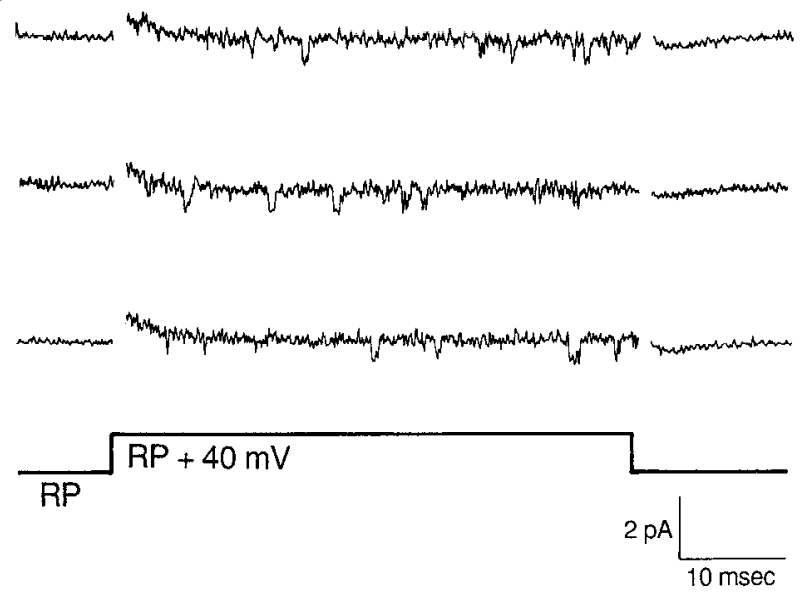

B.

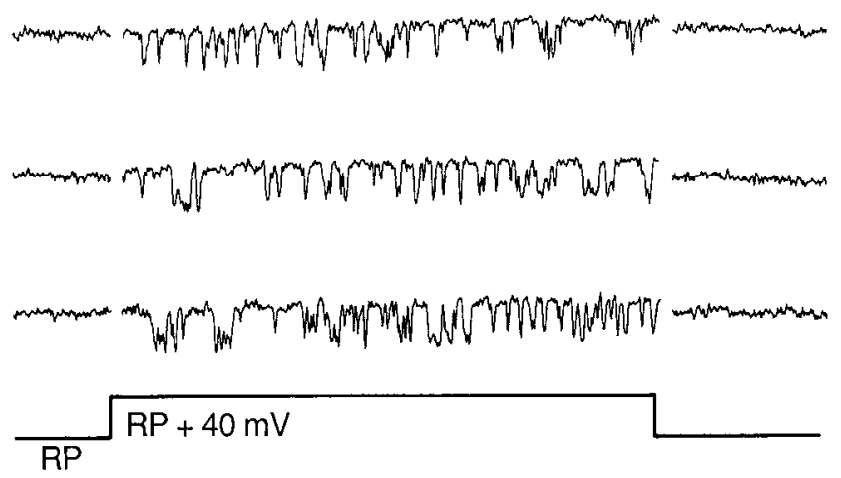

Figure 3. Two species of calcium channels present in TPA-trcated bag cell neurons. $A$, Recording from a cell-attached patch containing the small-conductance (12 pS) calcium channel. This species of calcium channel was the only species present in patches from control cells and was also present in patches from cells that were treated with $20 \mathrm{~nm}$ TPA. $B$, Example of the large-conductance $(24 \mathrm{pS})$ calcium channel. This species of calcium channel was present in TPA-treated cells $(n=$ 9 cells from 3 animals) but was never observed in cells treated with TPA 15-30 min after addition of $10 \mu \mathrm{M}$ sphinganine ( $n=7$ cells from 2 animals).

(Hidaka et al., 1984). Alternatively, the spike broadening that occurs during an afterdischarge may depend upon an interplay of PKC-induced modulation of calcium current and cyclic AMPdependent modulation of potassium or other currents. If this is the case, spike broadening may respond more variably to inhibition of PKC.

\section{Sphinganine and $H-7$ do not reverse TPA-induced enhancement of action potentials}

In theory, the effect of PKC on the calcium action potentials could depend on the continucd activation of $\mathrm{PKC}$ or could persist after PKC activity returns to its inactivated state. We used the PKC inhibitors to differentiate between these possibilities. Because $15 \mathrm{~min}$ preincubation of isolated bag cell neurons with the inhibitors is sufficient to block the effect of TPA (Fig. 2; Conn et al., 1989), it appears that $15 \mathrm{~min}$ is sufficient time for these inhibitors to reach and inhibit PKC in intact cells. Therefore, we measured the effect of $10 \mu \mathrm{M}$ sphinganine and $100 \mu \mathrm{M} \mathrm{H}-7$ on action potential height in isolated cells that were 
Figure 4. Sphinganine and $\mathrm{H}-7$ do not inhibit the expression of a long-lasting afterdischarge in bag cell clusters. Data shown are extracellular recordings of afterdischarges of compound action potentials that were triggered in bag cell clusters in control, $\mathrm{H}-7(100 \mu \mathrm{M})$-treated, and sphinganine $(25 \mu \mathrm{M})$-treated abdominal ganglia by stimulation of the pleuroabdominal afferent nerve to the abdominal ganglion. Data shown arc representative of 7 control, 7 sphinganine-treated, and 4 H-7-treated abdominal ganglia, each from a separate animal.
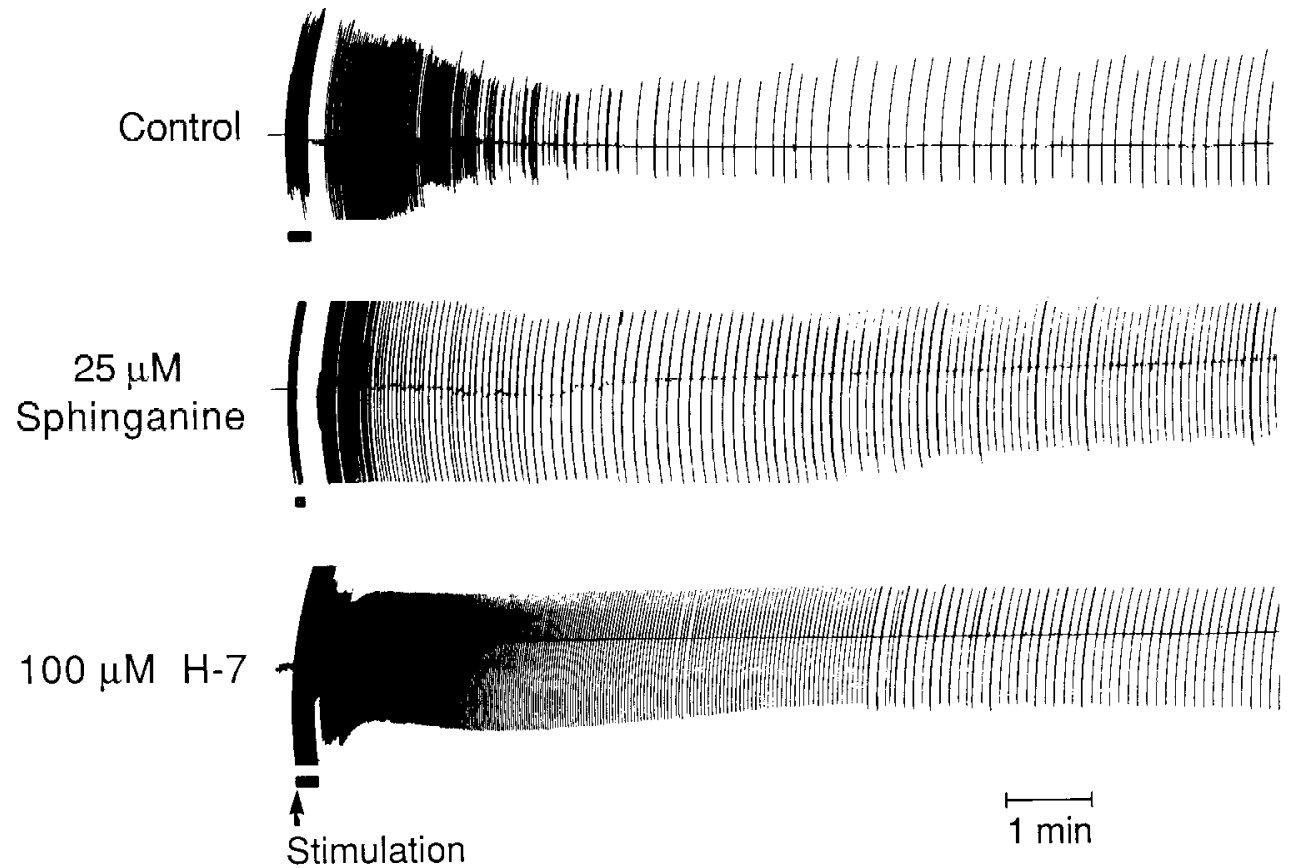

pretreated with $20 \mathrm{~nm}$ TPA to determine whether inhibition of PKC reverses the effect of TPA within a similar time period (Fig. 6).

After stable baseline action potentials were obtained, TPA was added and action potential height was monitored. Sphinganine $(10 \mu \mathrm{M})$ or $\mathrm{H}-7(100 \mu \mathrm{M})$ was added after a significant enhancement of action potential height had been observed. This was $20 \mathrm{~min}$ after TPA addition in all cases but one in which sphinganine was added $30 \mathrm{~min}$ after TPA addition. Action potential height was then monitored for a further $60 \mathrm{~min}$ after addition of the inhibitor. Action potential height either continued to rise or remained stable in all of the 6 cells studied (Fig. 6). In no case did action potential height decrease after addition of the inhibitor. These data suggest that although activation of PKC can induce a long-lasting transformation in the excitability of bag cell neurons, the maintenance of this transformed state does not require continued activation of the enzyme.

\section{Discussion}

The present finding that sphinganine inhibits TPA-induced enhancement of action potentials and calcium currents in bag cell neurons from Aplysia agrees with the finding reported in the accompanying paper (Conn ct al., 1989) that the structurally distinct protein kinase inhibitor $\mathrm{H}-7$ inhibits the effects of TPA on these cells. Also consistent with the results obtained with $\mathrm{H}-7$, we found that sphinganine does not inhibit control calcium currents in cells not treated with TPA. Furthermore, the finding that an analog of sphinganine that does not inhibit PKC $(N-$ acetylsphinganine) does not inhibit the effect of TPA on action potential height or calcium current amplitude suggests that the effect of sphinganine is not mediated by a nonspecific effect of this compound. These data, taken together with previous studies showing that a variety of phorbol ester activators of PKC (but not phorbol esters that do not activate $\mathrm{PKC}$ ) and microinjection of purified PKC mimic the effect of TPA (DeReimer et al., 1985; Strong et al., 1987), provide very strong support for the interpretation that calcium current in these cells is modulated by PKC.
A major goal of the present study was to use the PKC inhibitors to analyze of the role of PKC and the covert calcium channel in the afterdischarge and subsequent inhibited period of bag cell neurons within the intact abdominal ganglion. We found that the afterdischarge can be initiated in the presence of $\mathrm{H}-7$ and sphinganine and that extracellular recordings of afterdischarges in H-7- and sphinganine-treated ganglia show no major differences in their basic characteristics compared with controls. However, in normal untreated clusters of bag cell neurons, the height and width of bag cell action potentials is significantly increased within the first 2 min of the afterdischarge. This is thought to be related to second messenger-induced changes in excitability of the bag cell neurons and to promote the further release of neuroactive peptides from the cells. Both $\mathrm{H}-7$ and sphinganine inhibited this enhancement of action potentials during the afterdischarge, suggesting that PKC plays a key role in modulation of action potential shape during the afterdischarge. It is interesting that the PKC inhibitors prevented all of the action potential enhancement since cAMP-PK-induced modulation of currents is also likely to regulate the excitability of these cells (Kaczmarek et al., 1986; Strong and Kaczmarek, 1986 , for reviews). There are a number of possible explanations for this. In contrast to isolated cclls, the observed action potential enhancement in intact clusters of cells may require the coordinated actions of both PKC and cAMP-PK. For example, it is possible that without the $\mathrm{PKC}$-induced increase in calcium current, the action potential is shortened such that the currents modulated by cAMP-PK do not play a major role in influencing action potential shape. Alternatively, PKC activation may be required for maximal activation of adenylate cyclase in bag cell neurons, as has been shown to occur in other cell systems (Bell et al., 1985; Sibley et al., 1986; Yoshimasa et al., 1987). Testing of this hypothesis must await development of selective cAMPPK inhibitors that can be bath applied.

Another effect of PKC inhibitors was to produce an increase in the duration of afterdischarges. This difference reached statistical significance in $\mathrm{H}-7$ but not sphinganine-treated ganglia. Therefore, we do not know whether this effect is directly related 

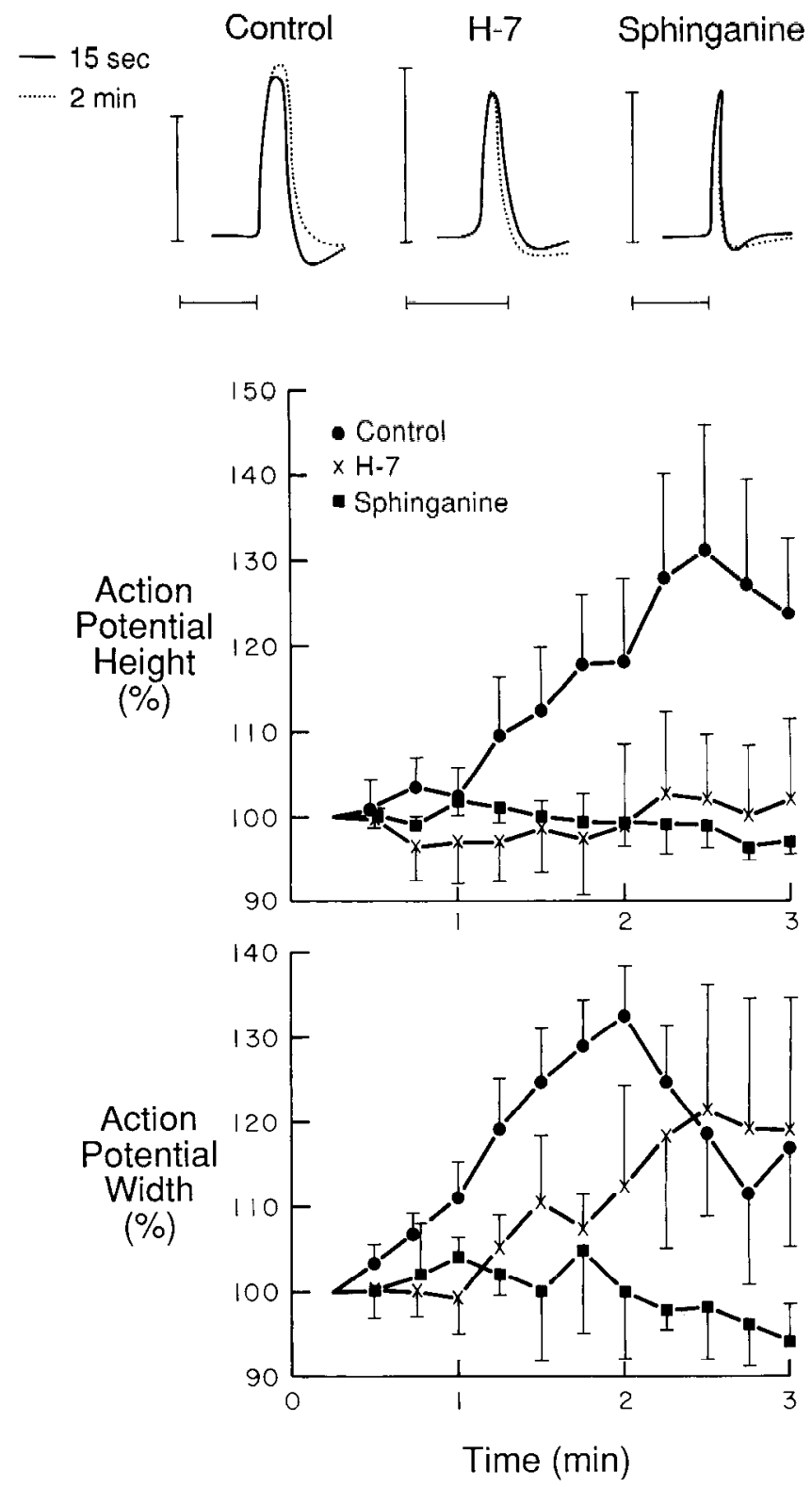

Figure 5. Sphinganine and H-7 prevent enhancement of action potentials that occurs during the bag cell neuronal discharge. The upper traces show intracellular recordings of action potentials in bag cell neurons in intact abdominal ganglia at the onset of an afterdischarge and in the same cells 2 min into an afterdischarge. Action potentials are shown for a control ganglion, a ganglion treated with $100 \mu \mathrm{M} \mathrm{H}-7$, and a ganglion treated with $25 \mu \mathrm{M}$ sphinganine. Scale bars, $50 \mathrm{mV}, 200 \mathrm{msec}$. The bottom graph shows the time course of the mean ( \pm SEM) height and width of action potentials from control $(n=7)$, H-7-treated $(n=$ 4 ), and sphinganine-treated $(n=4)$ ganglia (each from a separate animal) during the first $3 \mathrm{~min}$ of afterdischarge.

to the inhibition of PKC. However, evidence suggests that calcium plays a key role in the termination of the afterdischarge and in the initiation of the refractory period (Kaczmarek and Kauer, 1983). It is possible that inhibition of PKC and of the unmasking of the covert calcium channel results in less accumulation of intracellular calcium during the afterdischarge and thereby prolongs the afterdischarge.

We have shown that although sphinganine and $\mathrm{H}-7$ prevent the TPA-induced enhancement of excitability in isolated cells, these agents have no detectable effect when added after the
A. $100 \mu \mathrm{M} \mathrm{H}-7$
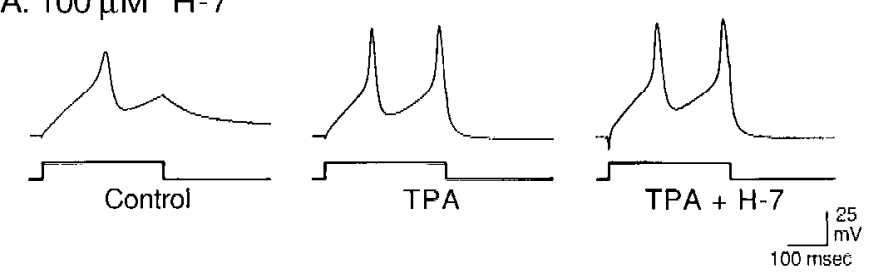

B.

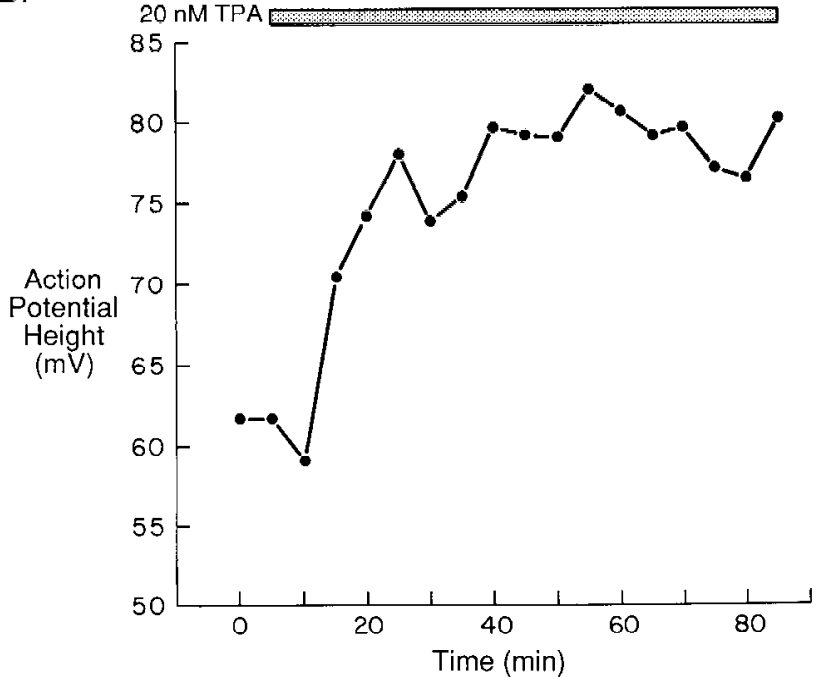

Figure 6. PKC inhibitors do not reverse TPA-induced enhancement of action potentials in bag cell neurons. Action potentials were evoked by injection of a fixed depolarizing current (100-200 pA) into cultured bag ccll ncurons from a resting potential of -40 to $-60 \mathrm{mV}$. When necessary, resting potential was maintained at a constant level by injection of holding current. Baseline action potential shape was established prior to addition of $20 \mathrm{nM}$ TPA. Sphinganine $(10 \mu \mathrm{M})$ or H-7 $(100 \mu \mathrm{M})$ was added $20 \mathrm{~min}$ after TPA addition in all but one cell, in which sphinganine was added $30 \mathrm{~min}$ after TPA. Action potentials were then elicited at the rate of $1 / \mathrm{min}$ for $1 \mathrm{hr}$ after addition of the inhibitor. $A$, Action potentials elicited immediately prior to TPA addition, 20 min after TPA addition (immediately prior to addition of $\mathrm{H}-7$ ), and 1 hr after addition of $\mathrm{H}-7 . B$. Time course of the effect of $\mathrm{H}-7$ on the height of action potentials evoked from the cell depicted above. These data are representative of $3 \mathrm{H}$-7-treated cells (from 2 animals) and 3 sphinganine-treated cells (from 3 animals). In a cell from another animal, TPA enhanced spike height and induced spontaneous firing of action potentials at the resting potential used. These action potentials continued for the $1 \mathrm{hr}$ period after sphinganine addition.

enhancement of action potentials has already taken place. In other cell systems H-7 inhibits PKC when added after the enzyme has been activated with TPA (Fujita et al., 1986), and it is also likely that sphinganine reverses TPA-induced activation of PKC since it interacts in a competitive manner at the phorbol ester binding site (Hannun et al., 1986). Thus, the simplest interpretation of the present finding is that the calcium currents of bag cell neurons undergo a lasting change in function in response to a brief activation of PKC and that this change persists for at least $45 \mathrm{~min}$ (and possibly longer) in the absence of PKC activity. The time course of PKC activation during an afterdischarge has not yet been measured. The present findings, however, indicate that only a transient activation of the enzyme at the onset of the discharge could be sufficient to enhance calcium current for the entire duration of the afterdischarge.

The mechanism of the persistence of PKC-activated calcium current in bag cell neurons is not known at present. One pro- 
posed mechanism for persistent modulation of neuronal excitability involves the generation of autonomous protein kinases that are active in the absence of the second messenger that induced the initial response (Schwartz and Greenberg, 1987). This is a plausible possibility for PKC since proteolytic cleavage of this enzyme with the calcium-dependent protease calpain generates an autonomous form of the enzyme that is active in the absence of phospholipids or calcium (Kishimoto et al., 1983). It is possible that this form of the enzyme is generated upon activation of PKC with phorbol esters in bag cell neurons and that the autonomous enzyme is insensitive to inhibition by $\mathrm{H}-7$ and sphinganine. However, if $\mathrm{H}-7$ acts primarily by competing with ATP at the catalytic site of PKC, as experiments have suggested (Hidaka et al., 1984), then its ability to inhibit the enzyme would be expected to be independent of the presence of the regulatory domain.

An equally plausible mechanism for the persistent effect of activation of $\mathrm{PKC}$ is that activation of the enzyme induces expression of the covert calcium channel in an irreversible manner and that, once expressed, the covert channel remains functional in the absence of PKC activation. For example, PKC could induce expression of the covert calcium channel by stimulating translocation of the channel from intracellular vesicles to the plasma membrane. In this case, once inserted into the membrane, the channel could remain active even in the absence of PKC activity. This could explain the previous finding that TPA fails to enhance calcium current if added after the cell has been dialyzed (DeReimer et al., 1985; Strong et al., 1987). Future studies will be needed to evaluate each of these possibilities.

In conclusion, our data suggest that the PKC-induced expression of a covert calcium channel in bag cell neurons is a longlasting effect that may be maintained in the absence of PKC activity and that this effect of $\mathrm{PKC}$ is responsible for enhancing action potentials during the afterdischarge in Aplysia bag cell neurons. A persistent change in neuronal excitability, which endures after its initiating stimulus and second messengers have been inactivated, may play a rolc in many long-lasting animal behaviors and may also contribute to short- and long-term memory (Schwartz and Greenberg, 1986).

\section{References}

Alkon, D. L., M. Kubota, J. T. Neary, S. Naito, D. Coulter, and H. Rasmussen (1986) C-kinase activation prolongs $\mathrm{Ca}^{++}$-dependent inactivation of $\mathrm{K}^{+}$currents. Biochem. Biophys. Res. Commun. 134: $1245-1253$.

Bell, J. D., I. L. Buxton, and I. I. Brunton (1985) Enhancement of adenylate cyclase activity in $\$ 49$ lymphoma cells by phorbol esters: Putative effect of $\mathrm{C}$ kinase on alpha $\mathrm{s}_{\mathrm{s}}$-GTP-catalytic subunit interaction. J. Biol. Chem. 260: 2625-2628.

Berry, R. W. (1986) Calcium and protein kinase C inhibit biosynthesis of Aplysia egg-laying hormone. Mol. Brain Res. 1: 185-187.

Conn, P. J., J. A. Strong, and L. K. Kaczmarek (1987) Protein kinase $\mathrm{C}$ inhibitors prevent phorbol ester-induced increases in calcium currents in Aplysia bag cell neurons. Soc. Neurosci. Abstr. 13: 106.

Conn, P. J., J. A. Strong, and L. K. Kaczmarek (1988) Activity of protein kinase $\mathrm{C}(\mathrm{PKC})$-induced calcium channel persists after inactivation of the enzyme. Soc. Neurosci. Abstr. 14: 153.

Conn, P. J., J. S. Strong, E. M. Azhderian, A. C. Nairn, P. Greengard, and L. K. Kaczmarek (1989) Protein kinase inhibitors selectively block phorbol ester- or forskolin-induced changes in excitability of Aplysia neurons. J. Neurosci. 9: 473-479.

DeReimer, S. A., J. A. Strong, K. A. Albert, P. Greengard, and L. K. Kazmarek (1985) Enhancement of calcium current in Aplysia neurons by phorbol ester and protein kinase C. Nature 313: 313-316.

Farley, J., and S. Auerbach (1986) Reductions of potassium currents and enhancement of calcium current in Hermissenda photoreceptors by phorbol ester and protein kinase C. Nature 319: 220-223.

Fink, L. A., J. A. Connor, and L. K. Kaczmarek (1988) Inositol trisphosphate releases intracellularly stored calcium and modulates ion channels in molluscan neurons. J. Neurosci. 8: 2544-2555.

Fujita, I., K. Takeshige, and S. Minakami (1986) Inhibition of neutrophil superoxide formation by 1 -(5-isoquinolinesulfonyl)-2-methylpiperazine (H-7), an inhibitor of protein kinase-C. Biochem. Pharmacol. 35: 4555-4562.

Hannun, Y. A., C. R. Loomis, A. H. Merrill, Jr., and R. M. Bell (1986) Sphingosine inhibition of protein kinase $\mathrm{C}$ activity and of phorbol dibutyrate binding in vitro and in human platelets. J. Biol. Chem. 261: 12604-12609.

Hidaka, H. M. Inagaki, S. Kawamoto, and Y. Sasaki (1984) Isoquinolinesulfonamides, novel and potent inhibitors of cyclic nucleotidedependent protein kinase and protein kinase C. Biochemistry 23: 5036-5041.

Ho, A. K., and D. C. Klein (1987) Activation of alpha-1 adrenoceptors, protein kinase $\mathrm{C}$, or treatment with intracellular free $\mathrm{Ca}^{++}$elevating agents increases pineal phospholipase $\mathrm{A} 2$ activity: Evidence that protein kinase $\mathrm{C}$ may participate in $\mathrm{Ca}^{++}$-dependent alpha- 1 adrenergic stimulation of pineal phospholipase A2 activity. J. Biol. Chem. 262: $11764-11770$.

Kaczmarek, L. K. (1987) The role of protein kinase C in the regulation of ion channels and neurotransmitter release. Trends Neurosci. 10: $30-34$.

Kaczmarek, L. K., and J. A. Kauer (1983) Calcium entry causes a prolonged refractory period in peptidergic neurons of Aplysia. J. Neurosci. 3: 2230-2239.

Kaczmarek, L. K., K. R. Jennings, and F. Strumwasser (1982) An early sodium and late calcium phase in the afterdischarge of peptide secreting neurons of Aplysia. Brain Res. 238: 105-115.

Kaczmarek, L. K., J. A. Strong, and J. A. Kauer (1986) The role of protein kinases in the control of prolonged changes in neuronal excitability. Prog. Brain. Res. 69: 77-90.

Kelleher, D. J., J. E. Pessin, A. Ruoho, and G. L. Johnson (1984) Phorbol ester induces desensitization of adenylate cyclase and phosphorylation of beta-adrenergic receptor in turkey erythrocytes. Proc. Natl. Acad. Sci. USA 81: 4316-4320.

Kishimoto, A., N. Kajikawa, M. Shiotu, and Y. Nishizuka (1983) Proteolytic activation of calcium-activated, phospholipid-dependent protein kinase by calcium-dependent neutral protease. J. Biol. Chem. 258: 1156-1164.

Kupfermann, I., and E. R. Kandel (1970) Electrophysiological properties and functional interconnections of two symmetrical neurosecretory clusters (bag cells) in abdominal ganglion of Aplysia. J. Neurophysiol. 33: 865-876.

Litchfield, D. W., and E. H. Bell (1986) Phosphorylation of cytoskelctal protein talin by protein kinase C. Biochem. Biophys. Res. Commun. 134: $1276-1283$.

Madison, D. V., R. C. Malenka, and R. A. Nicoll (1986) Phorbol esters block voltage-sensitive chloride current in hippocampal pyramidal cells. Nature 321:695-697.

Malenka, R. C., D. V. Madison, R. Andrade, and R. A. Nicoll (1986) Phorbol esters mimic some cholinergic actions in hippocampal pyramidal neurons. J. Neurosci. 6: 475-480.

Merrill, A. H., Jr., A. M. Sereni, V. L. Stevens, Y. A. Hannun, R. M. Bell, and J. M. Kinkade (1986) Inhibition of phorbol ester-dependent differentiation of human promyelocytic leukemic (HL-60) cells by sphinganine and other long-chain bases. J. Biol. Chem. 261: 12610 12615 .

Miller, R. J. (1986) Protein kinase C: A key regulator of ncuronal excitability? Trends Neurosci. 9: 538-541.

Nichols, R. A., J. W. Haycock, J. K. T. Wang, and P. Greengard (1987) Phorbol ester enhancement of neurotransmitter release from rat brain synaptosomes. J. Neurochem. 48: 615-621.

Publicover, S. J. (1985) Stimulation of spontaneous transmitter release by the phorbol ester 12-O-tetradecanoylphorbol-13-acetate. Brain Res. 333: 185-187.

Schwartz, J. H., and S. M. Greenberg (1987) Molecular mechanisms for memory: Second-messenger induced modifications of protein kinases in nerve cells. Annu. Rev. Neurosci. 10: 459-476.

Shapira, R., S. D. Silberberg, S. Ginsgurg, and R. Rahamimoff (1987) Activation of protein kinase $C$ augments evoked transmitter release. Nature 325: 58-61. 
Sibley, D. R., P. Nambi, J. R. Peters, and R. J. Lefkowitz (1984) Phorbol diesters promote alpha-adrenergic receptor phosphorylation and adenylate cyclase desensitization in duck erythrocytes. Biochem. Biophys. Res. Commun. 121: 937-979.

Sibley, D. R., R. A. Jeffs, K. Daniel, P. Nambi, and R. J. Lefkowitz (1986) Phorbol diester treatment promotes enhanced adenylate cyclase activity in frog erythrocytes. Arch. Biochem. Biophys. 244:373381.

Strong, J. A., and L. K. Kaczmarek (1986) Multiple components of delayed potassium current in peptidergic neurons of Aplysia: Modulation by an activator of adenylate cyclase. J. Neurosci. 6: 814-822.

Strong. J. A., and L. K. Kaczmarek (1987) Potassium currents that regulate action potentials and repetitive firing. In Neuromodulation, L. K. Kaczmarek and I. B. Levitan, eds., pp. 119-137, Oxford U. P., New York.

Strong, J. A., A. P. Fox, R. W. Tsien, and L. K. Kaczmarek (1987) Stimulation of protein kinase $\mathrm{C}$ recruits covert calcium channels in Aplysia bag ccll ncurons. Naturc 325: 714-717.

Vicentini, L. M., F. Di Virgilio, A. Ambrosini, T. Pozzan, and J. Meldolesi (1985) Tumor promoter phorbol 12-myristate, 13-acetate inhibits phosphoinositide hydrolysis and cytosolic calcium rise induced by activation of muscarinic receptors in PC12 cells. Biochem. Biophys. Res. Commun. 127: 310-317.

Wang, M., A. L. Cahill, and R. L. Perlman (1986) Phorbol 12,13dibutyrate increases tyrosine hydroxylase activity in superior cervical ganglion of the rat. J. Neurochem. 46: 388-393.

Werth, D. K., J. E. Niedel, and I. Pastan (1983) Vinculin, a cytoskeletal substrate for protein kinase C. J. Biol. Chem. 258: 11423-11426.

Wilson, E., M. C. Olcott, R. M. Bell, A. H. Merrill, Jr., and D. Lambeth (1986) Inhibition of the oxidative burst in human neutrophils by sphingoid long-chain bases: Role of protein kinase $\mathrm{C}$ in activation of the burst. J. Biol. Chem. 261: 12616-12623.

Yoshimasa, T., D. Sibley, M. Bonvier, R. J. Lefkowitz, and M. G. Caron (1987) Cross-talk between cellular signalling pathways suggested by phorbol-ester-induced adenylate cyclase phosphorylation. Nature 327 67-71.

Zurgil, N., and N. Zisapel (1985) Phorbol ester and calcium act syncrgistically to enhancc ncurotransmitter release by brain neurons in culture. FEBS Lett. 185: 257-261. 